\title{
Atıksulardan Zn Gideriminin Yapay Sinir Ağı (YSA) ile Modellenmesi
}

\author{
Fatma Erdem \\ Türkiye İlaç ve Tibbi Cihaz Kurumu, Ankara, Türkiye, (ORCID: 0000-0002-6014-6664), fatmaduran82@gmail.com
}

(2nd International Conference on Access to Recent Advances in Engineering and Digitalization (ARACONF)-10-12 March 2021)

(DOI: 10.31590 /ejosat.903854)

\begin{abstract}
ATIF/REFERENCE: Erdem, F. (2021). Atıksulardan Zn Gideriminin Yapay Sinir Ağı (YSA) ile Modellenmesi. Avrupa Bilim ve
\end{abstract} Teknoloji Dergisi, (24), 335-342.

\section{$\ddot{O} \mathbf{z}$}

Yapılan bu çalışmada Ankara Sanayi Odası 2. ve 3. Organize Sanayi Bölgesi atıksu arıtma tesisi için Zn giderim tahmini YSA ile gerçekleştirilmiştir. Toksik olup ağır metal kirliliği kapsamında atıksularda oldukça sık karşılaşılan çinkonun arıtım sonrası belirlenen limite indirgenmesi oldukça önemlidir. YSA ile modelleme çalışmalarında giriş parametresi olarak giriş pH, Zn ve Fe konsantrasyonu, AKM ( Askıda Katı Madde) ve TKM (Toplam Katı Madde) seçilirken çıkış parametresi olarak Zn çıkış konsantrasyonu seçilmiştir. Verilerin eğitimi Levenberg-Marquardt ileri besleme algoritması ile yapılmış olup deneysel veriler \%75 eğitim, \%15 validasyon ve \%15 test olarak ayrılmıştır. Çalışmada giriş parametreleri için farklı kombinasyonların oluşturduğu senaryolar denenmiş ve sisteme ait maksimum devir (epoch) değeri, eğitim, validasyon ve tüm biyosorpsiyon sistemi için R ve MSE değeri belirlenerek elde edilen sonuçlar karşılaştırılmıştır. Aktivasyon fonksiyonunun sonuçlar üzerine etkisini görebilmek için tansig, pürelin ve logsis transfer fonksiyonları kullanılmıştır. Çalışma sonucunda deneysel ve model tahmini çıkış akımındaki Zn konsantrasyon değerleri karşılaştırıldığında, YSA ile sistemin iyi bir şekilde modellendiği ve modelin iyi bir tahmin yeteneğine sahip olduğu görülmüştür.

Anahtar Kelimeler: Atıksu, Modelleme, Çinko, Yapay Sinir A ̆̆̆.

\section{Modeling of Zn Removal from Wastewater with Artificial Neural Network (ANN)}

\begin{abstract}
In this study, Zn removal estimation for the Ankara Chamber of Industry 2nd and 3rd Organized Industrial Zone wastewater treatment plant was performed by Artificial Neural Network (ANN). It is very important to reduce the zinc, which is toxic and frequently encountered in wastewater within the scope of heavy metal pollution, to the limit determined after treatment. In the modeling studies, $\mathrm{pH}, \mathrm{Zn}$ and Fe concentration, SS (Suspended Solids) and TSS (Total Suspended Solids) were selected as input parameters, while Zn output concentration was chosen as the output parameter. The training of the data was done with the Levenberg-Marquardt feed forward algorithm and the experimental data were divided into $75 \%$ training, $15 \%$ validation and $15 \%$ test. In the study, scenarios created by different combinations for input parameters were tried and the results obtained by determining the maximum cycle (epoch) value of the system, training, validation and R and MSE values for the whole biosorption system were compared. In order to see the effect of activation function on the results, tansig, purelin and logsis transfer functions were used. As a result of the study, when the $\mathrm{Zn}$ concentration values in the experimental and the model estimated output current were compared, it was seen that the system was well modeled with ANN and the model has a good prediction ability.
\end{abstract}

Keywords: Wastewater, Modeling, Zinc, Artificial Neural Network. 


\section{Giriş}

Atık sudaki en yaygın kimyasal kirleticiler arasında ağır metal katyonlar, hidrokarbonlar, pestisitler, azotlu bileşikler, farmasötik kalıntılar, deterjanlar ve fosfor ile hayvan ve insan vücut atıklarından kaynaklı mikrobiyolojik kontaminasyon bulunmaktadir (Agoro vd., 2020).

$\mathrm{Bu}$ kirleticilerden güçlü bir etkiye sahip ağır metaller nispeten yüksek bir yoğunluğa sahip olup düşük konsantrasyonlarda bile toksik veya zehirli olan herhangi bir metalik elementi ifade etmektedir. Ağır metal atıklar son yıllarda atık suya deşarjı, akut toksisiteleri, biyolojik olarak parçalanamazlıkları ve yüksek konsantrasyonlarda birikmeleri nedeniyle kaçınılmaz olarak küresel su ortamında metalik maddelerin artmasına neden olmaktadır (Pugazhenthiran ve Anandan, 2015). Bu durum sonucu su alıcı tüm canlılar için çeşitli sorunlar oluşabilmekte insanlarda kanser, sinir sisteminde hasar ve en aşırı örneklerde de ölüme sebep olabilmektedir (P. Prabhu ve P. Prabhu, 2018). İnsan sağlığı için belirli bir düzeyde çinko içeriği gerekli iken yüksek konsantrasyonlarda da verdiği zarar oldukça fazladır (John vd., 2016).

Çinko, parlak mavimsi beyaz, oldukça reaktif bir metaldir. Çeliğin galvanizlenmesinde, bazı alaşımların hazırlanmasında, gübre, böcek ilaçları, elektrik pillerinde negatif plaka imalatına kullanılmaktadır. Pigment olarak çinko plastik, kozmetik, fotokopi kağıdı, duvar kağıdı, baskı mürekkepleri vb. ürünlerde kullanılırken, kauçuk üretiminde üretim sırasında katalizör ve nihai üründe 1sı dağıtıcı olarak görev yapmaktır (Raut vd., 2012; Mishra, 2014).

Çinko sahip olduğu bu geniş kullanım alanı dolayısı ile atık sulardan uzaklaştırılması, endüstride geniş bir yelpazede çinko varlığı nedeniyle geniş bir araştırma alanıdır ve literatürde fiziksel, kimyasal ve biyolojik arıtım yöntemleri çalışılmıştır (Kulkarni, 2015). Zn arıtımı giriş suyundaki çinko konsantrasyonu nispeten düşükse, çinkonun (özellikle çözünmüş çinkonun) geleneksel aktif çamur arıtımı ile çıkarılmasının zorluğunu ortaya koymuştur (Yamagata vd., 2009). Bu nedenle atıksulardan $\mathrm{Zn}$ giderimi özel stratejilerin gerekli olduğu bir arıtım işlemidir.

Atıksu arıtma süreçleri, içeri giren atık su akış hızı, konsantrasyonu ve bileşimindeki büyük farklılıklar nedeniyle doğal olarak dinamiktir. Kentleşme ve sanayiye bağlı artan atıksu oluşumu daha etkin ve verimli çalışan arıtma tesislerine ihtiyacı artırmaktadır. Ancak birçok atıksu arıtma tesisinin tasarım ve işletme hatalarından dolayı tam verimle çalışamaması söz konusudur. Mevcut tesislerin mevzuatın zorunlu kıldığı deşarj standartlarını sağlayamaması veya işletme maliyetlerinin yüksek olması iyileştirme ve optimizasyon ihtiyacını beraberinde getirmekte ve bu nedenle atıksu aritım tesislerinde modelleme çalışmaları önem kazanmaktadır (Çınar ve Yılmaz, 2005; Philips vd., 2005).

Modelleme çalışmalarında yer alan akıllı yöntemler ile arıtım tesisleri gibi karmaşık prosesler modellenebilmektedir. Bulanık mantık ve istatistiksel süreç kontrolü, tesisin geçmiş işletim verilerinden yararlanılarak kullanılmaktadır ancak örneklerden öğrenebilen YSA'nın karşılaşılan birçok ek sorun için daha iyi çözüm seçenekleri sunduğu yapılan çalışmalarda görülmüştür (Boger, 1992; Kırım, 2015).
Literatürde Buaisha ve ark., çinko, nikel ve bakır gibi ağır metallerin atıksudan uzaklaştırılmasında YSA modelini kullanmışlardır. 10 nöronlu gizli katmanda sigmoid transfer fonksiyonu (tansig) ve çıktı katmanında doğrusal transfer fonksiyonu (purelin) kullanarak sırasıyla $0.98,0.84$ ve $0.99 \mathrm{R}^{2}$ değeri elde etmişlerdir (Buaisha, 2019). Yıldız çalışmasında fistık kabuğu ile Ni giderimini gizli katmanda 6 nöronlu üç katmanlı YSA kullanılarak başarıyla tahmin etmiştir (Yıldız, 2018). Nemeček ve ark., çalışmalarında Rhytidiadelphus squarrosus yosunundan hazırlanan biyosorbent ile $\mathrm{Cd}, \mathrm{Zn}$ ve Co iyonlarının tekli ve iki bileşenli çözeltilerinden giderimini tahmin etmek için YSA kullanmışlardır. $\mathrm{R}^{2}=0.996$ ve $\mathrm{R}^{2}=0.987$ değerleri ile YSA nın sistemi başarılı bir şekilde ifade ettiği görülmüştür (Nemeček vd., 2014). Alizamir ve ark., Asadabad ovasının yeraltı su kaynaklarındaki As, $\mathrm{Pb}$ ve $\mathrm{Zn}$ konsantrasyonunu tahmin etmek için ileri beslemeli YSA geliştirmişler ve eğitim algoritması olarak Levenberg-Marquardt (LM) ile Bayesian düzenlileştirme (BR) algoritmalarını kullanmışlardır. As, $\mathrm{Pb}$ ve $\mathrm{Zn}$ için $\mathrm{R}^{2}$ değeri sirasiyla $0.9288,0.9823$ ve 0.8876 olarak bulunmuştur (Alizamir ve Sobhanardakini, 2016). Javan ve ark., çinko giderimi için YSA ve MLP yöntemlerini kullanmış olup YSA'nın $R^{2} 0.98-1$ ve kök ortalama kare hatasi RMSE'nin 0.7-0.01 ile sistemi daha iyi modellediği belirlenmiştir (Javan vd., 2019). Fard ve ark., kurşun ve çinkonun yeraltı suyundaki ağır metal dağılımının belirlenmesi için YSA ve MANFIS ile modelleme çalışmaları yapmışlar ve MANFIS modelinin, ağır metallerin yeraltı suyundaki dağılımını yüksek bir doğruluk ve sağlamlıkla tahmin etme potansiyeline sahip olduğunu göstermişlerdir (Fard vd., 2017).

Yapılan bu çalışmada Ankara Sanayi Odası 2. ve 3. Organize Sanayi Bölgesi Atık $\mathrm{Su}$ arıtma tesisinde gerçekleştirilen $\mathrm{Zn}$ giderimi YSA ile incelenmiştir. Tesis giriş ve çıkışında ölçülen pH, TKM, AKM, Fe, Zn gibi parametreler giriş değişkeni olarak sisteme tanımlanırken çıkış akımındaki $\mathrm{Zn}$ konsantrasyonu tahmini gerçekleştirilmiştir.

\section{Materyal ve Metot}

\subsection{Yapay Sinir A ğı (YSA)}

Bilgisayarlar ve bilgisayar sistemleri yaşamımızın vazgeçilmez bir parçası haline gelirken geçmiş yıllarda sadece hesap yapabilirken ya da veri transferleri gerçekleştirirken kullanılan bilgisayarlar ile artık büyük miktardaki verileri özetleyen ve bu verileri kullanarak olaylar hakkında yorumlar yapabilen, olaylar arasındaki ilişkiyi çözümleyen özellikler kazanmıştır (Ağyer, 2015). YSA çeşitli problemlere çözüm getirmek amaciyla insan beyninin bilgi işleme mekanizmasını taklit ederek geliştirilmiş bilgisayar yazılımlarıdır. İnsan beyni gibi biyolojik bir sinir ağının benzetimiyle oluşturulmuş YSA öğrenme, hafızaya alma ve öğrendiklerini yeni bilgiler üretecek biçimde genelleme, değişkenler arasındaki ilişkileri ortaya koyma yeteneklerine sahiptirler. Milyarlarca birbirine bağlı nörondan oluşan memelilerin beyninin, yüz tanıma, vücut hareket planlaması ve kas aktivitelerinin kontrolü gibi karmaşık ve hesaplama gerektiren görevlerle başa çıkma yeteneğine sahip olduğu iyi bilinmektedir. Şekil 1, bir nöronunun hücresel bir yapısını göstermektedir. Nöron yapısından esinlenerek, YSA biyolojik nöron sisteminin öğrenme yeteneğini taklit etmek için geliştirilmiştir. YSA kavramı ilk olarak McCulloch ve Pitts tarafindan 1940'larda araştırılmıştır. Temel olarak YSA matematiksel modeli, doğrusal olmayan dinamik kalıpları tahmin etmek için çekici öğrenme yeteneği ve hesaplama gücüne sahip, 
giriş katmanı, gizli katman ve çıktı katmanı olmak üzere üç katmanlı bir yapıdan oluşmaktadır (Yazıcı, 2007).

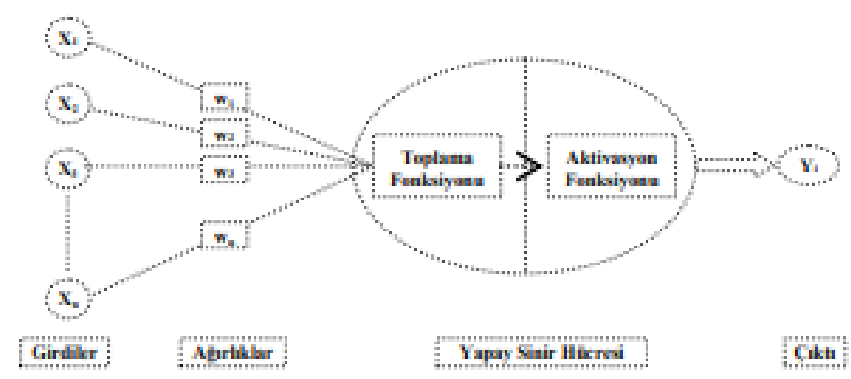

Şekil 1. Yapay sinir hücresi genel yapısı

Gizli katman ve çıktı katmanında bulunan yapay sinir hücrelerinin net girdisi bir önceki katmandaki sinir hücrelerinin çıkısından alınan sayısal verilerin bağlantı ağırlıkları (wi) ile çarpılarak toplama fonksiyonu yardımıyla toplanması ile net çıktı ise hesaplanan net girdi değerinin transfer ya da diğer adıyla aktivasyon fonksiyonu ile işlenmesi ile hesaplanmaktadır (Eren ve Eyüpoğlu, 2011).

\subsection{Yapay Sinir Ăğı Yapılanması}

YSA'nın başarılı bir şekilde modelleme işlemini gerçekleştirebilmesi için ağ mimarisi oldukça önem taşımaktadır. $\mathrm{Bu}$ yapılanma sırasında öncelikle giriş ve çıkış değerlerinin seçimi önem taşır.

Çıkış değeri modellenmesi amaç edilen ve maksimize edilmeye çalışılan değer olarak seçilirken giriş değişkenleri proses parametrelerinde maksimize edilen değer üzerinde etkisi olduğu belirlenmiş veriler üzerinden seçilir (F. Panchal, M. Panchal, 2014). Gizli katman giriş ve çıkış arasındaki ara katmandır. Aktivasyon fonksiyonu bu gizli katman üzerinde etkilidir ve gizli nöronlardan oluşur. Gizli nöron sayısı belirlenmesinde de genel olarak deneme yanılma yöntemi kullanılmaktadır (Arifin vd., 2019; Gupta ve Raza, 2020). YSA model geliştirme sürecinde diğer bir önemli basamak veri seti bölme işlemidir. Eğitim serisi model parametrelerinin optimizasyonunda kullanılır. Test seti eğitim sırasında çapraz doğrulama yaparak aşırı öğrenme (overfitting) sorununu engeller. Validasyon seti ise eğitilen modelin performansını değerlendirmekte görev alır. 75:15:15, 60:20:20,...gibi farklı oranlar kullanılmakta olup genel olarak veri setinin büyük olduğu sistemlerde 75:15:15 dağılımı tercih edilmektedir (Wu vd., 2012).

\subsection{Veri normalleştirme}

Normalizasyon işlemi YSA analizinde girdi ve çıktı için eğitim ve test basamağından önce yapılması gerekli olup verilere karşılaştırılabilir aralık sağlayarak her bir girdi değişkeninin öneminin eşit olarak dağıtılmasını önemli ölçüde etkilemektedir (Akıllı ve Atıl, 2020). Ayarlanmış min. max yöntemi ile Denklem 1 'deki gibi ağların verimliliğini artırmak için 0.1 ila 0.9 aralığında normalize edilerek veri setinin boyutsuz bir form alması sağlanmaktadır (Aksu vd., 2019).
$X_{i}=0.8 \frac{\left(X-X_{\min }\right)}{\left(X_{\max }-X_{\min }\right)}+0.1$

$\mathrm{X}_{\mathrm{i}}$ normalize edilecek değer, $\mathrm{X}$ ölçülen değer, $\mathrm{X}_{\min } \mathrm{X}$ için en küçük değer, $X_{\max } X$ için en büyük değer

\subsection{Zn giderimine Yapay Sinir Ăğ Yaklaşımı}

Atıksu arıtma tesisine ait giriş ve çıkış akımları için mevcut $\mathrm{Zn}, \mathrm{Cr}$, toplam fosfor, COD, SO4 ve renk gibi çeşitli parametreler temin edilmiş olup $\mathrm{Zn}$ giderimi sırasında bağımsız değişkenlerin birbiri ile ilişkisini anlamlandırmak için SPSS ile korelasyon analizi yapılmıştır.

YSA yapılanmasında giriş değişkeni olarak $\mathrm{pH}$, giriş $\mathrm{Zn}$ ve Fe konsantrasyonu, AKM ve TKM kullanırken çıktı katmanında çıkış akımındaki Zn konsantrasyon değeri tahmin edilmiştir. Sistem parametreleri arasındaki korelasyon değerine göre sisteme girdi olarak farklı senaryolar (Tablo 1) tanımlanmıştır. YSA uygulaması MATLAB R2017a ile Neural Fitting toolbox uygulaması ile gerçekleştirilmiştir.

Tablo 1.YSA için tanımlanan farklı giriş değişkenleri

\begin{tabular}{|c|c|c|}
\hline Senaryo & Giriş Değişkeni & Çıkış Değişkeni \\
\hline 1 & $\begin{array}{c}\text { Zn, Fe, } \mathrm{pH}, \mathrm{AKM}, \\
\mathrm{TKM}\end{array}$ & $\mathrm{Zn}$ \\
\hline 2 & $\mathrm{Zn}, \mathrm{Fe}, \mathrm{AKM}, \mathrm{TKM}$ & $\mathrm{Zn}$ \\
\hline 3 & $\mathrm{Zn}, \mathrm{Fe}, \mathrm{AKM}$, & $\mathrm{Zn}$ \\
\hline 4 & $\mathrm{Zn}, \mathrm{Fe}$ & $\mathrm{Zn}$ \\
\hline 5 & $\mathrm{Zn}$ & $\mathrm{Zn}$ \\
\hline
\end{tabular}

\section{Araştırma Sonuçları ve Tartışma}

Zn giderimi için mevcut verilerin birbirleri arasındaki ilişkiyi tespit etmek amacı ile kullanılan SPSS programı sonuçlarını içeren Tablo 2 incelendiğinde $\mathrm{Zn}$ ile $\mathrm{Cr}$, toplam fosfor, $\mathrm{COD}, \mathrm{SO}_{4}$ ve renk parametrelerinin negatif ilişkili olduğu görülürken $\mathrm{Zn}$ 'nin pozitif korelasyon değerine sahip olduğu $\mathrm{pH}$, TKN, TKM, Zn ve $\mathrm{Fe}$ konsantrasyonu giriş verisi olarak YSA sistemine tanımlanmıştır. Ayrıca değişkenlere ait standart sapma, minimum, maksimum, ortalama değerlerde SPSS aracılı̆̆ ile hesaplanmıştır (Tablo 3) . 
Tablo 2. Pearson korelasyon katsaylsının parametreler arası sonuçları

Correlations

\begin{tabular}{|c|c|c|c|c|c|c|c|c|c|c|c|c|}
\hline & & $\mathrm{Zn}$ & $\mathrm{Fe}$ & $\mathrm{Cr}$ & TKN & Tfosfor & $\mathrm{COD}$ & $\mathrm{pH}$ & AKM & $\mathrm{SO} 4$ & Renk & İletkenlik \\
\hline \multirow[t]{3}{*}{$\mathrm{Zn}$} & $\begin{array}{l}\text { Pearson } \\
\text { Correlation }\end{array}$ & 1 &, $779^{* *}$ &,- 235 & ,168 &,- 160 &,- 037 &, 115 &, $444^{* *}$ &,- 071 &,- 089 &,- 051 \\
\hline & Sig. (2-tailed) & &, 000 & ,144 & ,300 & ,324 & ,819 & ,479 & ,004 & ,663 &, 584 & ,753 \\
\hline & $\mathrm{N}$ & 40 & 40 & 40 & 40 & 40 & 40 & 40 & 40 & 40 & 40 & 40 \\
\hline \multirow[t]{3}{*}{$\mathrm{Fe}$} & $\begin{array}{l}\text { Pearson } \\
\text { Correlation }\end{array}$ &, $779^{* *}$ & 1 &,- 142 & ,157 &,- 093 &,- 210 & ,077 &, $375^{*}$ &,- 193 & ,097 &,- 077 \\
\hline & Sig. (2-tailed) &, 000 & & ,382 & ,334 &, 570 & 193, & 636, & ,017, & 232 & ,551, & ,638 \\
\hline & $\mathrm{N}$ & 40 & 40 & 40 & 40 & 40 & 40 & 40 & 40 & 40 & 40 & 40 \\
\hline \multirow[t]{3}{*}{$\mathrm{Cr}$} & $\begin{array}{l}\text { Pearson } \\
\text { Correlation }\end{array}$ &,- 235 &,- 142 & 1 & ,093 & ,209 &,- 072 &, 251 &, 073 &,- 059 &,- 050 &, 014 \\
\hline & Sig. (2-tailed) & ,144 & ,382 & & ,568 & , 195 & ,658 & ,118 & ,656 & ,715 & ,762 & ,929 \\
\hline & $\mathrm{N}$ & 40 & 40 & 40 & 40 & 40 & 40 & 40 & 40 & 40 & 40 & 40 \\
\hline \multirow[t]{3}{*}{ TKN } & $\begin{array}{l}\text { Pearson } \\
\text { Correlation }\end{array}$ & , 168 &, 157 & ,093 & 1 &,- 102 &,- 006 &,- 071 &, $355^{*}$ & , 136 & ,278 &,- 115 \\
\hline & Sig. (2-tailed) & ,300 & ,334 & ,568 & & ,531 & ,971 & ,661 & ,025 & , 404 & ,082 & , 478 \\
\hline & $\mathrm{N}$ & 40 & 40 & 40 & 40 & 40 & 40 & 40 & 40 & 40 & 40 & 40 \\
\hline \multirow[t]{3}{*}{$\begin{array}{l}\text { Tfosfo } \\
r\end{array}$} & $\begin{array}{l}\text { Pearson } \\
\text { Correlation }\end{array}$ &,- 160 & & ,209 &,- 102 & 1 &, 021 & &,- 124 &,- 065 &,- 254 &, 179 \\
\hline & Sig. (2-tailed) &, 324 &, 570 & ,195 &, 531 & & ,899 &, 571 & ,447 & ,692 &, 114 & ,268 \\
\hline & $\mathrm{N}$ & 40 & 40 & 40 & 40 & 40 & 40 & 40 & 40 & 40 & 40 & 40 \\
\hline \multirow[t]{3}{*}{ COD } & $\begin{array}{l}\text { Pearson } \\
\text { Correlation }\end{array}$ &,- 037 &,- 210 &,- 072 &,- 006 & ,021 & 1 &, $394^{*}$ & ,293 & ,024 &, $351^{*}$ &,- 282 \\
\hline & Sig. (2-tailed) &, 819 & ,193 & ,658 & ,971 & ,899 & & ,012 & ,066 & ,882 &, 026 & ,078 \\
\hline & $\mathrm{N}$ & 40 & 40 & 40 & 40 & 40 & 40 & 40 & 40 & 40 & 40 & 40 \\
\hline \multirow[t]{3}{*}{$\mathrm{pH}$} & $\begin{array}{l}\text { Pearson } \\
\text { Correlation }\end{array}$ & ,115 &, 077 & ,251 &,- 071 &,- 092 &, $394^{*}$ & 1 &, $352^{*}$ &,$- 407^{* *}$ & ,252 &,- 109 \\
\hline & Sig. (2-tailed) & ,479 & ,636 &, 118 & ,661 &, 571 &, 012 & & ,026 & ,009 &, 117 &, 503 \\
\hline & $\mathrm{N}$ & 40 & 40 & 40 & 40 & 40 & 40 & 40 & 40 & 40 & 40 & 40 \\
\hline \multirow[t]{3}{*}{ AKM } & $\begin{array}{l}\text { Pearson } \\
\text { Correlation }\end{array}$ &, $444^{* *}$ &, $375^{*}$ & ,073 &, $355^{*}$ &,- 124 & ,293 &, $352^{*}$ & 1 &,- 037 & ,297 &,- 184 \\
\hline & Sig. (2-tailed) &, 004 &, 017 & ,656 & ,025 & ,447 & ,066 & ,026 & & ,823 & ,063 & ,256 \\
\hline & $\mathrm{N}$ & 40 & 40 & 40 & 40 & 40 & 40 & 40 & 40 & 40 & 40 & 40 \\
\hline \multirow[t]{3}{*}{$\mathrm{SO} 4$} & $\begin{array}{l}\text { Pearson } \\
\text { Correlation }\end{array}$ &,- 071 &,- 193 &,- 059 & ,136 &,- 065 & ,024 &,$- 407^{* *}$ &,- 037 & 1 & ,005 & , 187 \\
\hline & Sig. (2-tailed) & ,663 &, 232 &, 715 & , 404 & ,692 & ,882 &, 009 &, 823 & & ,976 &, 247 \\
\hline & $\mathrm{N}$ & 40 & 40 & 40 & 40 & 40 & 40 & 40 & 40 & 40 & 40 & 40 \\
\hline Renk & $\begin{array}{l}\text { Pearson } \\
\text { Correlation }\end{array}$ &,- 089 & 097, &,- 050 & ,278 &,- 254 &, $351^{*}$ &, 252 & ,297 & 005, & 1 &,- 068 \\
\hline
\end{tabular}


European Journal of Science and Technology

\begin{tabular}{|ll|c|c|c|c|c|c|c|c|c|c|c|}
\multicolumn{1}{|c|}{ Sig. (2-tailed) } &, 584 &, 551 &, 762 &, 082 &, 114 &, 026 &, 117 &, 063 &, 976 & &, 675 \\
$\mathrm{~N}$ & 40 & 40 & 40 & 40 & 40 & 40 & 40 & 40 & 40 & 40 & 40 \\
\hline $\begin{array}{l}\text { İletken } \\
\text { lik Pearson }\end{array}$ & Correlation &,- 051 &,- 077 &, 014 &,- 115 &, 179 &,- 282 &,- 109 &,- 184 &, 187 &,- 068 & 1 \\
& Sig. (2-tailed) &, 753 &, 638 &, 929 &, 478 &, 268 &, 078 &, 503 &, 256 &, 247 &, 675 & \\
& $\mathrm{~N}$ & 40 & 40 & 40 & 40 & 40 & 40 & 40 & 40 & 40 & 40 & 40 \\
\hline
\end{tabular}

**. Correlation is significant at the 0.01 level (2-tailed).

*. Correlation is significant at the 0.05 level (2-tailed).

Tablo 3. Giriş parametrelerinin istatistiksel analizi

\begin{tabular}{|l|c|c|c|c|c|}
\hline & $\mathrm{N}$ & Minimum & Maximum & Mean & Std. Deviation \\
\hline $\mathrm{Zn}$ & 40 &, 25 & 1,57 &, 6649 &, 29102 \\
$\mathrm{Fe}$ & 40 &, 83 & 8,70 & 3,1550 & 1,98490 \\
$\mathrm{Cr}$ & 40 &, 02 & 82,00 & 2,1947 & 12,94238 \\
$\mathrm{TKN}$ & 40 & 14,14 & 55,41 & 34,4718 & 12,28422 \\
$\mathrm{Tfosfor}$ & 40 & 1,25 & 8,79 & 4,2373 & 2,49596 \\
$\mathrm{COD}$ & 40 & 71,76 & 869,69 & 368,4923 & 176,27026 \\
$\mathrm{pH}$ & 40 & 7,20 & 9,75 & 8,1660 &, 41393 \\
$\mathrm{AKM}$ & 40 & 15,00 & 530,00 & 179,6022 & 108,88258 \\
$\mathrm{SO} 4$ & 40 & 106,60 & 2880,00 & 344,5256 & 484,09824 \\
Renk & 40 & 43,91 & 761,53 & 147,1548 & 157,20483 \\
İletkenlik & 40 & 1600,00 & 3900,00 & 2996,2750 & 421,63376 \\
Valid N (listwise) & & & & & \\
\hline
\end{tabular}


Sistem için transfer fonksiyonu olarak tansig fonksiyonu seçilmiş olup gizli nöron sayısı deneme yanılma yöntemi ile 15 olarak belirlenmiştir.

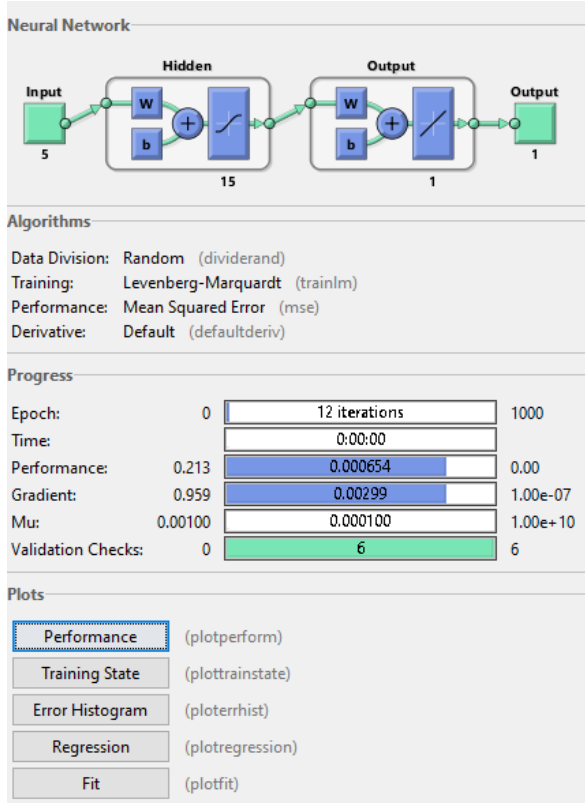

Şekil 2. YSA topolojisi

Senaryo 1: Sisteme $\mathrm{Zn}, \mathrm{Fe}, \mathrm{TKN}, \mathrm{pH}$ ve AKM girdi değişken olarak tanımlandığında 12 iterasyon sonucunda $R$ değeri 0.85 olarak bulunurken MSE değeri eğitim, validasyon ve test için $2.05100 \mathrm{e}-3,8.42047 \mathrm{e}-3,2.65362 \mathrm{e}-2$ olarak belirlenmiş̧tir.
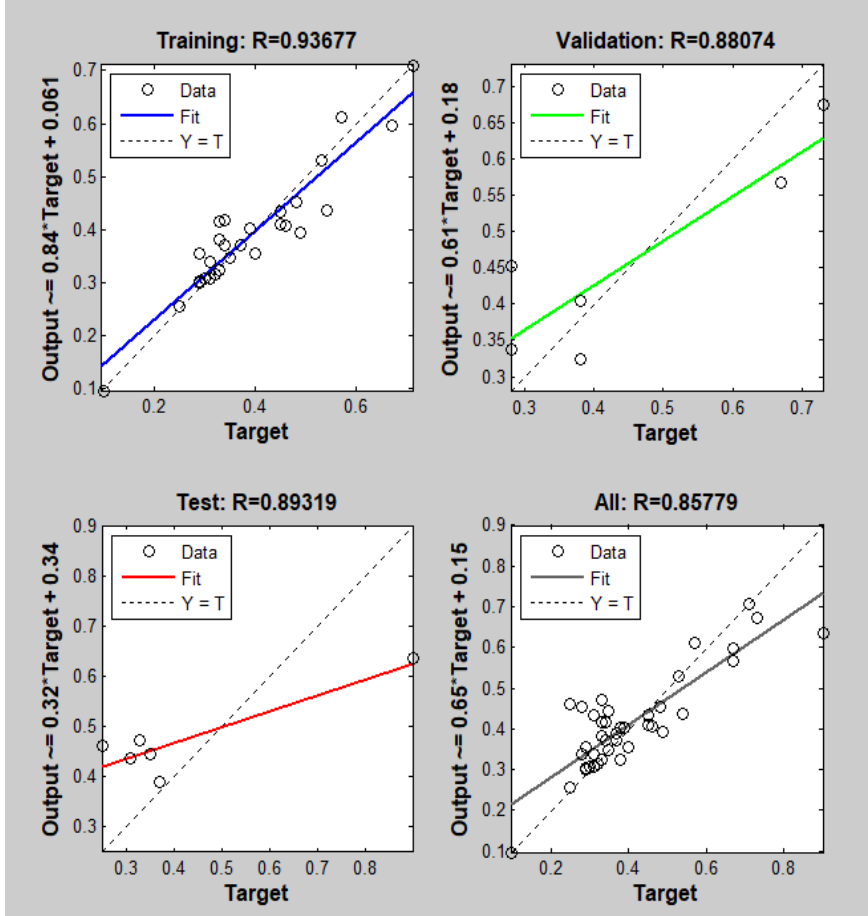

Şekil 3. YSA tahmin model grafiği (Zn, Fe, TKN, pH ve AKM girdi değişkenleri için)
Senaryo 2: Sisteme Zn, Fe, TKN ve AKM girdi değişken olarak tanımlandığında 16 iterasyon sonucunda $\mathrm{R}$ değeri 0.86 olarak bulunurken MSE değeri eğitim, validasyon ve test için 1.38925e-3, 7.82805-3, 2.98836e-2 olarak belirlenmiștir
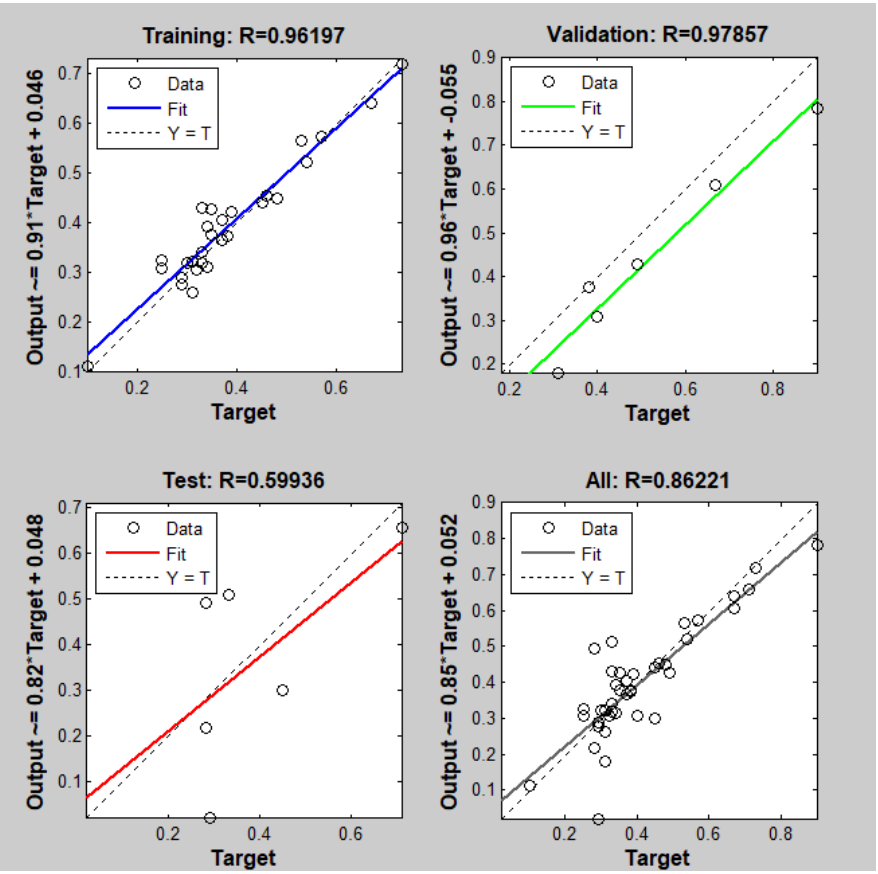

Şekil 4. YSA tahmin model grafiği (Zn, Fe, TKN ve AKM girdi değişkenleri için)

Senaryo 3: Sisteme Zn, Fe ve AKM girdi değişken olarak tanımlandığında 16 iterasyon sonucunda $\mathrm{R}$ değeri 0.87 olarak bulunurken MSE değeri eğitim, validasyon ve test için $9.04752 \mathrm{e}-$ 4, 3.62391e-2, 3.17289e-3 olarak belirlenmiştir.
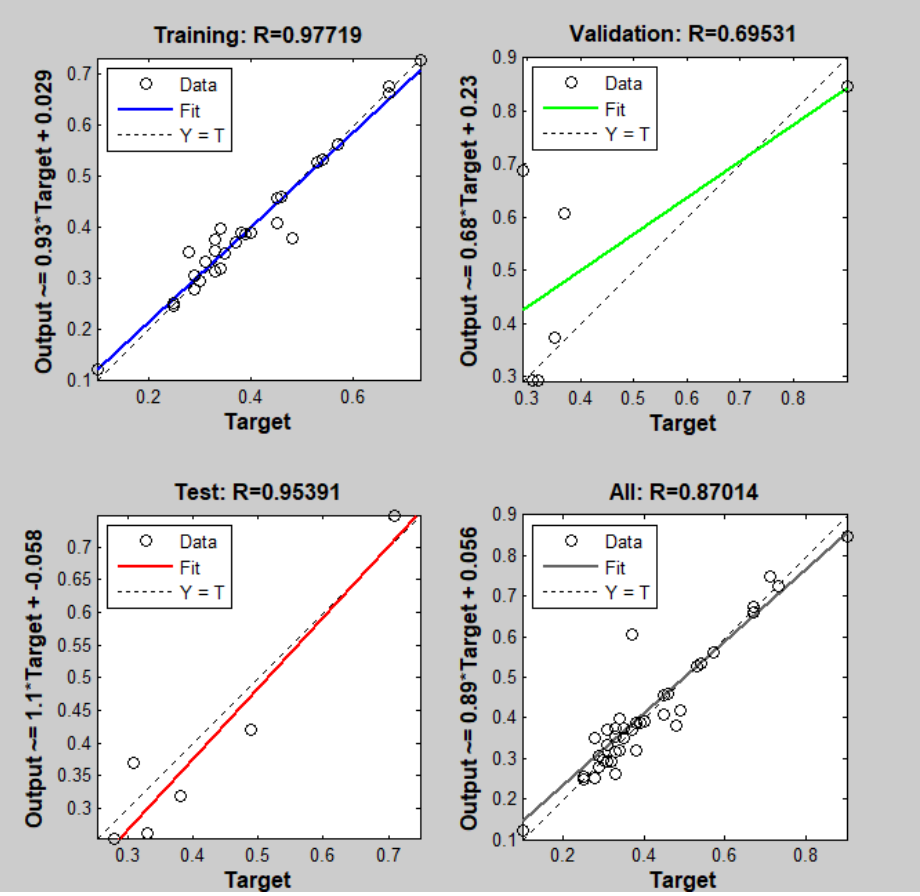

Şekil 5. YSA tahmin model grafiği (Zn, Fe ve AKM girdi değişkenleri için 
Senaryo 4: Sisteme $\mathrm{Zn}$ ve $\mathrm{Fe}$ girdi değişken olarak tanımlandığında 7 iterasyon sonucunda $\mathrm{R}$ değeri 0.89 olarakbulunurken MSE değeri eğitim, validasyon ve test için 2.33515e-3, 1.92133e-3, 4.14597e-3 olarak belirlenmiştir
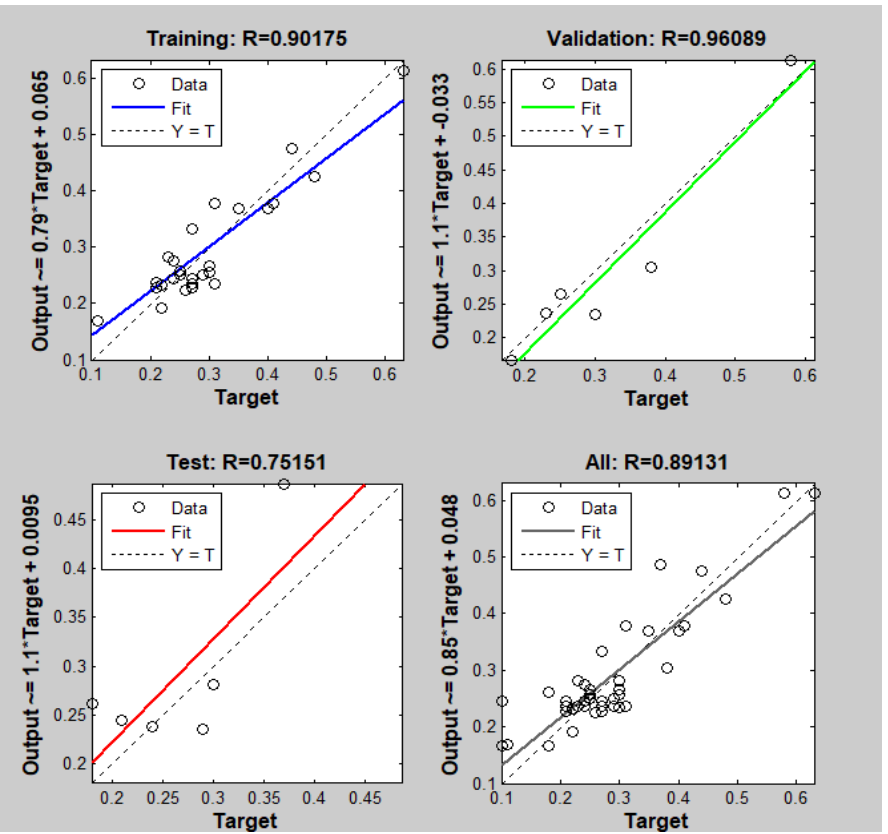

Şekil 6. YSA tahmin model grafiği (Zn ve Fe girdi değişkenleri için)

Senaryo 5: Sisteme Zn girdi değişken olarak tanımlandığında 64 iterasyon sonucunda $\mathrm{R}$ değeri 0.94 olarak bulunurken MSE değeri eğitim, validasyon ve test için $3.76808 \mathrm{e}-4,1.26644 \mathrm{e}-3$, 5.83412e-3 olarak belirlenmiştir.
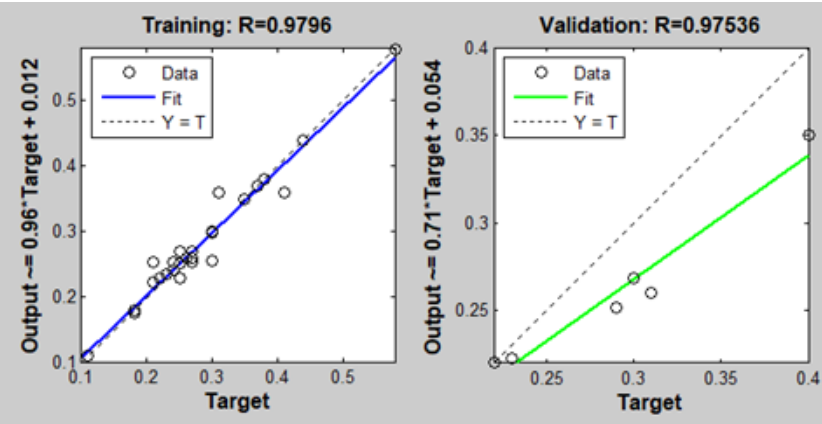

Test: $\mathbf{R}=\mathbf{0 . 9 2 5 5}$
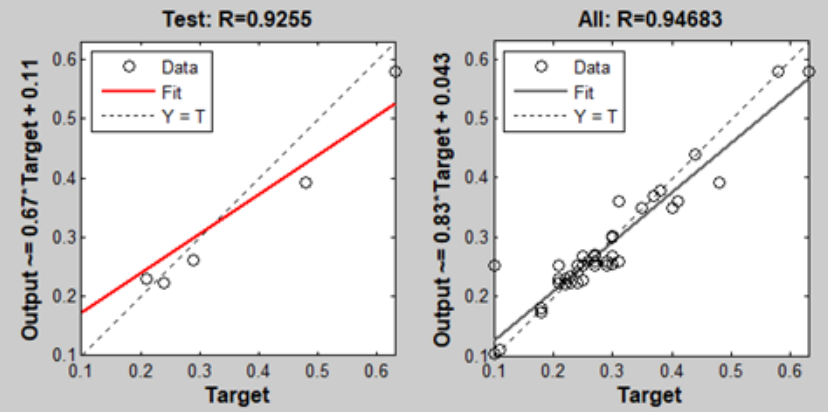

Şekil 7. YSA tahmin model grafiği (Zn girdi değişkeni için)
Elde edilen sonuçlar Tablo 4'te özetlenmiştir.

Tablo 4:farklı girdi değişkenleri için elde edilen $R$ değerleri

\begin{tabular}{|l|c|c|}
\hline & Giriş Değişkeni & R \\
\hline 1 & Zn, Fe, $\mathrm{pH}, \mathrm{AKM}, \mathrm{TKM}$ & 0.85 \\
\hline 2 & $\mathrm{Zn}, \mathrm{Fe}, \mathrm{AKM}, \mathrm{TKM}$ & 0.86 \\
\hline 3 & $\mathrm{Zn}, \mathrm{Fe}, \mathrm{AKM}$, & 0.87 \\
\hline 4 & $\mathrm{Zn}, \mathrm{Fe}$ & 0.89 \\
\hline 5 & $\mathrm{Zn}$ & 0.94 \\
\hline
\end{tabular}

\section{Sonuç}

Farklı giriş değişkenlerinin kombinasyonu ile oluşan çeşitli senaryolar ile modelleme çalışmaları gerçekleştirildiğinde en yüksek R değerine sisteme giriş değişkeni olarak sadece giriş $\mathrm{Zn}$ konsantrasyon değerinin verildiği sistem olmuştur. Literatürde giriş değişken sayısı arttıkça tahmin sonuçlarının doğruluğunun azalacağı yönündeki mevcut bilgi ile uyum sağlayan bir sonuç elde edilmiştir (Lake vd., 2009; Amini vd.,2005; Keshavarzia ve Sarmadian, 2020).

Yapılan modelleme çalışmalarında transfer fonksiyonu olarak tansig kullanıldığında 0.85 elde edilmiştir. Transfer fonksiyonunun sisteme olan etkisi incelenmek istenmiş olup logsis ve pürelin aktivasyon fonksiyonları kullanılarak Senaryo 1 için uygulama yapıldığında purelin ile $\mathrm{R}$ değeri 0.55 olarak elde edilirken logsis ile 0.77 elde edilmiştir.

Yapılan bu çalışma ile herhangi bir atıksu arıtma tesisinde başarılı bir şekilde arıtım sağlanarak mevzuatın zorunlu kıldığg deşarj standartların sağlanabilmesi açısından önem arz etmekte olup söz konusu tesis için YSA'nın başarılı bir şekilde sistemi modelleyebildiği görülmüştür.

\section{Teşekkür}

Ankara Sanayi Odası 2. ve 3. Organize Sanayi Bölgesi Atık $\mathrm{Su}$ Arıtma Tesisi, Çevre Yönetim ve Arıtma Müdürü, Çevre Mühendisi Enise Dilek ESEN'e veri paylaşımı için teşekkürlerimi sunarım.

\section{Kaynakça}

1. Agoro, M.A., Adeniji, A.O., Adefisoye, M.A., Okoh, O.O. (2020). Heavy Metals in Wastewater and Sewage Sludge from Selected Municipal Treatment Plants in Eastern Cape Province, South Africa. Water, 12,2746.

2. Pugazhenthiran, N., Anandan, S., Ashokkumar M. (2016) Removal of Heavy Metal from Wastewater. Handbook of Ultrasonics and Sonochemistry, Springer.

3. Prathisksha, P. Balakrishna, P. (2018) A Review on Removal of Heavy Metal Ions from Waste Water using Natural/ Modified Bentonite, J. MATEC Web of Conferences. 
4. John, M., Heuss-Aßbichler, S., Ullrich, A. (2016) Recovery of $\mathrm{Zn}$ from wastewater of zinc plating industry by precipitation of doped $\mathrm{ZnO}$ nanoparticles. Int. J. Environ. Sci. Technol. 13, 2127-2134.

5. Gakwisiri, C., Raut, N., Al-Saadi, A., Al-Aisri, S., Al-Ajmi, A. (2012). A Critical Review of Removal of Zinc from Wastewater. In Proceedings of the World Congress on Engineering, London, UK.

6. Mishra, V. (2014). Biosorption of zinc ion: a deep comprehension. Appl Water Sci, 4, 311-332.

7. Kulkarni, S.J. (2015). Removal of Zinc from Effluent: A Review. International Journal of Advanced Research in Science, Engineering and Technology, 2(1), 338-340.

8. Yamagata, H., Yoshizawa, M. \& Minamiyama, M. (2010). Assessment of current status of zinc in wastewater treatment plants to set effluent standards for protecting aquatic organisms in Japan. Environ Monit Assess., 169, 67-73.

9. Çınar, Ö., Yılmaz, A.S. (2005). Yapay Sinir Ağlarının Atıksu Arıtma Tesisi İşletimine Uygulanması: Bir Örnek Çalışma. KSÜ. Fen ve Mühendislik Dergisi, 8(2), 48-52.

10. Philips, N., Heyvaerts, S., Lammens, K., Van Impe, JF. (2005). Mathematical modelling of small wastewater treatment plants: power and limitations. Water Sci Technol., 51(10):47-54.

11. Boger, Z. (1992). Application of neural networks to water and wastewater treatment plant operation. ISA Transactions, 31(1), 25-33.

12. Kırım, G. (2015). Atıksu Arıtma Tesislerinin Model Desteği İle İyileştirilmesi Ve Optimizasyonu. Yüksek Lisans Tezi, İstanbul Teknik Üniversitesi, Fen Bilimleri Enstitüsü.

13. Buaisha, M., Balku, Ş., Yaman Özalp, Ş. (2019). ANNassisted forecasting of adsorption efficiency to remove heavy metals. Turkish Journal of Chemistry, 43(5), 1407-1424.

14. Yildiz, S. (2018) Artificial neural network approach for modeling of $\mathrm{Ni}$ (II) adsorption from aqueous solution by peanut shell. Ecol Chem Eng S., 25,581-604.

15. Nemeček, P., Kružlicová, D. Remenárová, L. (2014). Application of Ann for Prediction of $\mathrm{Co} 2+, \mathrm{Cd} 2+$ and $\mathrm{Zn} 2+$ Ions Uptake by R. Squarrosus Biomass in Single and Binary Mixtures, Nova Biotechnologica et Chimica., 13(1), 73-84.

16. Alizamir, M., Sobhanardakani, S. (2016). Forecasting of heavy metals concentration in groundwater resources of Asadabad plain using artificial neural network approach. Journal of Advances in Environmental Health Research, 4(2), 68-77.

17. Javan, S., Gholamalizadeh Ahangar, A., Hassani, A.H, Soltani, J. (2019). Estimation of Zn Bonds Using Multi-Layer Perceptron (MLP) Artificial Neural Network Method in Chahnimeh, Zabol. 7(2), 87-95.

18. Bayatzadeh Fard, Z., Ghadimi, F., Fattahi, H. (2017). Use of artificial intelligence techniques to predict distribution of heavy metals in groundwater of Lakan lead-zinc mine in Iran. Journal of Mining and Environment, 8(1), 35-48.

19. Ağyar, Z. (2015). Yapay Sinir Ağlarının Kullanım Alanları ve Bir Uygulama. Mühendis ve Makine, 56(662), 22-23.
20. Yazıcı, A.C., Öğüş, E., Ankaralı, S., Canan, S., Ankaralı, H., Akkuş, Z. (2007) Yapay Sinir Ağlarına Genel Bakış. Türkiye Klinikleri Tip Bilimleri Dergisi, 27(1), 65-71.

21. Eren, B., ve Eyüpoğlu, V. (2011). Yapay sinir ağları ile Ni(II)iyonu geri kazanım veriminin modellenmesi, 6th International Advanced Technologies Symposium, Elazığ.

22. Panchal, F.S., \& Panchal, M. (2014). Review on Methods of Selecting Number of Hidden Nodes in Artificial Neural Network. Computer Science, International Journal of Computer Science and Mobile Computing, 3(11), 455-464.

23. Arifin, F., Robbani, H., Annisa, T., Ma'arof, N N M I 2. (2019). Variations in the Number of Layers and the Number of Neurons in Artificial Neural Networks: Case Study of Pattern Recognition. Journal of Physics: Conference Series, 1413.

24. Gupta, T.K., Raza, K. (2020). Optimizing Deep Feedforward Neural Network Architecture: A Tabu Search Based Approach. Neural Process Lett., 51, 2855-2870.

25. Wu, W., May, R., Dandy, G.C, and Maier, H.R. (2012). A method for comparing data splitting approaches for developing hydrological ANN models. International Congress on Environmental Modelling and Software, 394.

26. Ak1llı, A., Atıl, H. (2020). Evaluation of Normalization Techniques on Neural Networks for the Prediction of 305Day Milk Yield. Turkish Journal of Agricultural Engineering Research, 1, 354-367.

27. Aksu, G., Güzeller, C., Eser, M. (2019). The Effect of the Normalization Method Used in Different Sample Sizes on the Success of Artificial Neural Network Model. International Journal of Assessment Tools in Education, 6(2), 170-192 .

28. Lake, H.R., Akbarzadeh A., Mehrjardi T. (2009). Development of pedotransfer functions (PTFs) to predict soil physico-chemical and hydrological characteristics in southern coastal zones of the Caspian Sea. Journal of Ecology and the Natural Environment., 1(7): 160-172.

29. Amini, M., Abbaspour K.C., Khademi H., Fathianpour, N., Afyuni, M., Schulin R. (2005). Neural network models to predict cation exchange capacity in arid regions of Iran. Eur. J. Soil Sci., 53: 748-757.

30. Keshavarzi, A., Sarmadian F. (2011).Comparison of Artificial Neural Network and Multivariate Regression Methods in Prediction of Soil Cation Exchange Capacity. International Journal of Environmental and Earth Sciences, 20111(1), 2530 . 